\title{
Gestão Pública Estadual e suas Nuances Lesbianas no Contexto Amazônico
}

Sebastiana SILVA

Gerência Diversidade e Gênero - GDG/DPDD/SEJUSC/AM

\begin{abstract}
A palestra "Gestão Pública Estadual e suas Nuances Lesbianas no Contexto Amazônico" foi realizada em 11 de novembro de 2017 na Universidade Federal da Bahia, em Salvador. Essa escrita é resultado de uma apresentação na jornada "Pensamento Lésbico Contemporâneo", uma atividade de extensão do GIRA - Grupo de Estudos Feministas em Política e Educação, em parceria com o Coletivo Lesbibahia. Nesse relato, busco visibilizar a construção da política pública de gênero e sexualidade na Gerência Diversidade e Gênero da Secretaria de Estado de Justiça, Direitos Humanos e Cidadania (SEJUSC) do estado do Amazonas, na perspectiva de uma equipe coordenada por uma lésbica negra, ativista, mãe, militante, feminista, servidora pública e filha da floresta amazônica.
\end{abstract}

PALAVRAS-Chave: Gestão Pública. Lesbianidades. Amazonas. Gênero. Diversidade. 
Nesse relato ${ }^{1}$, busco visibilizar a construção da política pública de promoção da cidadania LGBTI+, na coordenação da Gerência Diversidade e Gênero (GDG/DPDD/SEJUSC/AM) do estado do Amazonas, na perspectiva de uma lésbica negra, ativista, mãe, militante, feminista, servidora pública e filha da floresta amazônica. Nesse sentido, os diálogos e construções sempre levaram em conta a participação social e coletiva na implementação das políticas públicas de promoção e defesa dos direitos humanos, com foco na população LGBTI+, dentro da estrutura do Estado.

Tomo como ponto de partida o $11^{\circ}$ Encontro Brasileiro de Gays, Lésbicas e Travestis (EBGLT), organizado em 2003 pela Associação Amazonense de Gays, Lésbicas e Travestis (AAGLT) do Amazonas, cuja sede é a cidade de Manaus. Em 2005, após participar do $12^{\circ}$ EBGLT, em Brasília, após reflexão com o grupo de amigas, decidimos fundar a Associação Amazonense de Mulheres Independentes Pela Livre Expressão Sexual - AAMILES, composta por 32 mulheres Lésbicas e Bissexuais. No mesmo ano, fui eleita para a Secretaria Executiva do Conselho Municipal dos Direitos das Mulheres - CMDM, por aclamação. Em 2008, participei da I Conferência Nacional de Direitos Humanos e Politicas Públicas GLBTT, na qual fui eleita delegada pelo segmento lésbico. Em 2009, participamos do processo de eleição para a coordenação do Fórum LGBT Amazonas, em que fui eleita, por unanimidade, passando a coordenar esse fórum de forma colegiada e participativa, com a presença e ação efetiva das 22 instituições filiadas. Isto foi um marco histórico, por ser uma gestão lesbiana sapatônica, e significou também um grande desafio para o colegiado, para quem a liderança lésbica é algo com o qual não estão acostumados.

Assim, as instituições filiadas ao Fórum LGBT Amazonas, em sua maioria lideradas por homens gays e/ou por travestis, aos poucos se adaptaram à gestão, de modo que a credibilidade do fórum foi resgatada, ganhando a confiança dos parceiros e articulando ações de empoderamento dos ativistas através da colaboração dos movimentos sociais LGBTI+. Foi possível desenvolver várias ações pertinentes para a visibilidade da população LGBTI+, como as oficinas de lideranças jovens LGBT, o apoio à parada do orgulho LGBT, a realização, em parceria com

1 A minha participação na Jornada "Pensamento Lésbico Contemporâneo" foi possibilitada pelo edital PAEXDOC/UFBA de 2017. A passagem aérea foi oferecida pelo mandato da vereadora Aladilce Souza ( $\mathrm{PC}$ do $\mathrm{B})$. Agradecimentos pela revisão do texto à Sônia Jay Wright, Felipe Fernandes, Candy Laurendon, Frederico Soares e Igor Torres. 
o poder público estadual e os movimentos sociais, de encontros, seminários e rodas de conversas voltadas para a temática de direitos humanos e promoção da cidadania das pessoas LGBTI+. Ao decorrer dos anos, passaram a haver ações do governo, ainda que pontuais, de forma positiva e afirmativa, a exemplo de campanhas de combate à violência.

Precisávamos, porém, de ações, para além dessas afirmações; precisávamos fortalecer as políticas públicas, queríamos a oportunidade para enfrentar as desigualdades sociais e reduzir os altos índices de homicídios, violências e discriminações, até então não evidenciados pelos governos anteriores a 2014. Então, resolvemos tomar uma atitude coletivamente: propusemos aos candidatos ao pleito municipal de 20120 projeto Tripé da cidadania, para a implementação de políticas públicas para a população LGBT, amplamente debatido na II Conferência Estadual LGBT. Como tripé, entendemos a articulação das políticas públicas, particularmente através da criação de um conselho cujo objetivo é o monitoramento da execução de políticas, a publicação de um plano governamental com as metas a serem alcançadas e, por fim, a criação de uma gerência, que executa as ações previstas no plano.

Até o momento temos a criação do conselho e da gerência, mas ainda não foi elaborado o nosso plano que consolidará, de fato, as políticas de promoção e defesa dos direitos humanos dos LGBTI+ no estado do Amazonas. Articulamos, propomos e falamos aos quatros ventos sobre a importância de ter no estado uma política consolidada. $\mathrm{O}$ projeto, pensado em 2012 para o município, foi abraçado pelo governo do estado, com a criação da gerência Diversidade e Gênero, que passei a coordenar. Estamos, até o momento, lutando por essa tão sonhada política e seguiremos combativos até os serviços serem efetivados, não apenas no papel. Esse é o nosso desafio como Gerência de Diversidade e Gênero.

\section{Avanços}

Assinalamos abaixo os avanços conquistados, resultantes das lutas em prol dos direitos humanos de LGBTI+ no Amazonas:

- $\quad$ Aprovação da Lei $\mathrm{n}^{0}$ 3.079, de 02 de agosto de 2006. Dispõe sobre a prática de discriminação em razão de orientação sexual do indivíduo, a aplicação das penalidades decorrentes e outras providências (Combate à prática de discriminação LGBT); 
- Emissão da Portaria $\mathrm{n}^{0}$ 438/2009, da Secretaria de Estado de Assistência Social (SEAS), permitindo a utilização do nome social de travestis e transexuais em fichas de cadastro, formulários, prontuários e documentos congêneres, no atendimento prestado aos usuários de serviços nas unidades da SEAS;

- $\quad$ Foi firmado um Termo de Cooperação Técnica, nos termos do Decreto $\mathrm{n}^{0} 7.037$ de 21 de dezembro de 2009, atualizado pelo Decreto $\mathrm{n}^{\circ} 7.177$ de 12 de maio de 2010, para a articulação e implementação de políticas de enfrentamento às homofobias no Brasil;

- $\quad$ Edição da Resolução $n^{0} 33$ de 09 de abril de 2013, do Conselho Estadual de Educação, que estabelece normas para a utilização de nome social no Registro Escolar Interno das Escolas do Sistema Educacional do Amazonas;

- Criação do Comitê Estadual de Enfrentamento à Homofobia (CEHAM) em 29 de abril de 2013, com o objetivo de garantir os Direitos Humanos de forma universal, individual e interdependente, e de assegurar a cidadania plena e a promoção e defesa dos direitos humanos de LGBTs.

- $\quad$ Edição da Resolução ${ }^{0} 22$ de 30 de julho de 2013, do Conselho Estadual de Saúde, que dispõe sobre a inserção do nome social de travestis e transexuais em fichas de atendimento, prontuários, cartão do SUS e outros documentos internos de todas as unidades de saúde pública do Amazonas;

- Edição da Portaria $\mathrm{n}^{0}$ 057/2014 da Secretaria de Segurança Pública do Estado do Amazonas, que assegura às pessoas travestis e transexuais a identificação pelo nome social em documentos de prestação de serviço, em formulários eletrônicos ou em quaisquer outros documentos onde tenha que constar sua qualificação, quando do atendimento em órgãos que compõem o Sistema de Segurança Pública do Estado do Amazonas;

- $\quad$ Aprovação da Lei Delegada no 4. 263 de 09 de março de 2015, que cria a Secretaria de Estado de Justiça, 
Direitos Humanos e Cidadania - SEJUSC, e institui a Gerência Diversidade e Gênero;

- $\quad$ Aprovação da Lei ${ }^{0}$ 4.475, de 06 de maio de 2017, que dispõe sobre a criação do Conselho Estadual de Combate a Discriminação LGBT - CECOD;

- $\quad$ Edição da Portaria no 157 de 05 de outubro de 2017, que institui um Grupo de Trabalho com a finalidade de subsidiar a formulação de medidas de desburocratização nas ações de mudança no registro civil para as pessoas transexuais e travestis no âmbito dos cartórios de registro civil público do Estado do Amazonas.

\section{Retrocessos}

Assim como os avanços, assinalamos também retrocessos, que estão explicitados abaixo:

- Tramitação de Projeto de Lei $n^{0} 389$ /2015, que proíbe, na grade curricular da rede de ensino municipal de Manaus, a inclusão de atividades pedagógicas que visem à reprodução do conceito de "ideologia de gênero" (sic);

- Movimento contrário à discussão de conceitos de gênero, culminando na aprovação de planos municipais de educação contrários a nossas pautas;

- Ausência de Projetos de Lei que criminalizem a violência LGBTfóbica;

- $\quad$ Ausência de mecanismos estruturantes, a exemplo da Rede de Enfrentamento à Violência, de Delegacias Especializadas no Atendimento à Mulher e aos LGBTs, de Casas de Apoio e Ressocialização Familiar, de profissionais capacitados e sensibilizados na temática Direitos Humanos, Diversidade e Gênero e Sexualidade nas instituições públicas de justiça, saúde, etc.;

- $\quad$ Falta de programas de governo para promoção e defesa dos direitos humanos LGBT, bem como de campanhas de sensibilização a favor do respeito e da valorização da vida LGBT; 
- Falta de verba orçamentária proposta pelo legislativo estadual e municipal, deixando as ações pró-LGBTs sem recursos;

- $\quad$ Falta de debate nas casas legislativas;

- $\quad$ Falta de representatividade nas casas legislativas.

\section{Perspectivas Futuras}

Nossa meta é de que a violência contra a população LGBT no Brasil e no Amazonas deixe de ser uma realidade constante, motivada pela intolerância, incapacidade de aceitação, preconceito e discriminação. Que possamos viver a livre expressão do amor, da sexualidade e da identidade de gênero; que sejamos respeitadas e respeitados na condição de seres humanos; que não nos enquadrem na cultura heteronormativa, de moralidade fundamentalista, sexista, racista, misógina e LGBTfóbica.

\section{Conclusão}

Nesta exposição, pontuo que a gestão, para ser efetiva, precisa de articulação e apoio dos movimentos sociais e dos núcleos de pesquisas das universidades. Nosso compromisso com os segmentos sociais precisa ser fortalecido e pressionado de fora para dentro e de dentro para fora. $\mathrm{Na}$ gestão lesbiana, temos muitos desafios: em todos momentos: precisamos nos desdobrar para mostrar serviço e muitas vezes estamos sozinhas na tarefa de pensar e construir esse processo. Além disso, sofremos pressões internas e externas, por colegas dos movimentos sociais e da própria gestão, pelas nossas famílias, por nossas companheiras e, sobretudo, por nós mesmas: por sermos mulheres, pretas, lésbicas, ribeirinhas, periféricas. Assim, precisamos ter engajamento e uma atuação política coerente, na luta pela transformação real, pela valorização da vida das pessoas LGBT, em prol de uma sociedade sem racismo, sexismo e violência LGBTfóbica. 


\section{Referências}

ASSEMBLEIA LEGISLATIVA DO ESTADO DO AMAZONAS. Lei $\mathrm{n}^{0}$ 3079, de 02 de agosto de 2006. Dispõe sobre o combate à prática de discriminação em razão de orientação sexual do indivíduo, a aplicação das penalidades decorrentes e dá outras providências. [s.n]: Manaus, AM, 12 nov. 2006.

ASSEMBLEIA LEGISLATIVA DO ESTADO DO AMAZONAS. Lei $\mathrm{n}^{0}$ 5.475, de 06 de maio de 2017. Criação do Conselho Estadual de Combate à Discriminação LGBT - CECOD. [s.n.]: Manaus, AM, 2017.

BRASIL. Decreto $\mathrm{n}^{\mathrm{0}}$ 7037, de 21 de dezembro de 2009. Aprova o Programa Nacional de Direitos Humanos - PNDH-3 e dá outras providências. [s.n.]: Brasília, DF, 2009.

CÂMARA MUNICIPAL DE MANAUS. Projeto de Lei no 389 , de 24 de novembro de 2015. Proíbe na grade curricular das Escolas do Município de Manaus as atividades pedagógicas que visem à reprodução do conceito de ideologia de gênero. [s.n.]: Manaus, AM, 2015.

CONSELHO ESTADUAL DE EDUCAÇÃO. Resolução $\mathrm{n}^{\circ}$ 33, de 09 de abril de 2013. Estabelece normas para utilização de nome social no Registro Escolar Internos das Escolas do Sistema Educacional do Amazonas. [s.n.]: Manaus, AM, 2013.

CONSELHO ESTADUAL DE SAÚDE. Resolução $\mathrm{n}^{0}$ 22, de 30 de julho de 2013. Dispõe sobre a inserção do nome social de travestis e transexuais em fichas de atendimento, prontuários, cartão SUS, e outros documentos internos de todas as unidades de saúde pública do Amazonas. [s.n.]: Manaus, AM, 2013.

ASSEMBLEIA LEGISLATIVA DO ESTADO DO AMAZONAS. Lei $\mathrm{n}^{\mathrm{o}}$ 4163, de o9 de março de 2015. [s.n.]: Manaus, AM, 2015.

SECRETARIA DE ESTADO DE ASSISTÊNCIA SOCIAL E CIDADANIA. Portaria $n^{0} 438$, de 10 de dezembro de 2009. [s.n.]: Manaus, AM, 10 dez. 2009.

SECRETARIA DE SEGURANÇA PÚBLICA DO ESTADO DO AMAZONAS. Portaria ${ }^{0}$ 57, de 02 de abril de 2014. [s.n.]: Manaus, AM, 2014. 


\title{
Gestion Publique de l'Etat et ses Nuances Lesbiennes dans le Contexte de l'Amazone
}

\begin{abstract}
La conférence "Gestion Publique de l'Etat et ses Nuances Lesbiennes dans le Contexte de l'Amazone" a été réalisé le 11 Novembre 2017 à l'Université Fédérale de Bahia, à Salvador. Cet écrit est le résultat d'une présentation lors de la journée "Pensée Lesbienne Contemporraine", une activité de l'extension du GIRA - Groupe d'Etudes Féministes en Politique et Education, en partenariat avec le Collectif Lesbibahia. Dans cet écrit, je cherche à démontrer la construction de la politique publique de genre et sexualité dans la Gestion Diversité et Genre du Secrétariat de l'Etat de Justice, Droits Humains et Citoyenneté (SEJUSC) de l'état de l'Amazone, comme une équipe coordonnée par une lesbienne noire, activiste, mère, militante, féministe, fonctionnaire publique et fille de la forêt amazonienne.
\end{abstract}

KeyWords: Gestion Publique. Lesbiennetés. Amazone. Genre. Diversité.

Sebastiana SILVA

É ativista de direitos humanos e educadora social. Atualmente é gestora pública na Gerência Diversidade e Gênero do Departamento de Promoção e Defesas dos Direitos da Secretaria de Estado de Justiça, Direitos Humanos e Cidadania

(SEJUSC) 2015-2018, conselheira fiscal do movimento Manifesta LGBT+ de Manaus desde 2016, é membro fundador da Associação Amazonense de Mulheres Independente pela Livre Expressão Social (AAMILES). Foi Conselheira Municipal dos Direitos da Mulher de Manaus (2005-2009) e ex-coordenadora do Fórum 